\title{
Acoustic characterization of a neonate skull using a clinical MR-guided high intensity focused ultrasound system for pediatric neurological disorder treatment planning
}

\author{
Elodie Constanciel Colas ${ }^{*}$, Adam Waspe ${ }^{1}$, Charles Mougenot ${ }^{2}$, Thomas Looi ${ }^{1}$, Samuel Pichardo ${ }^{3}$, James Drake ${ }^{1}$ \\ From Current and Future Applications of Focused Ultrasound 2014. 4th International Symposium \\ Washington, D.C, USA. 12-16 October 2014
}

\section{Background/introduction}

Transcranial MR-guided Focused Ultrasound (TcMRgFUS) treatments are now clinically performed on adult patients for brain tumor or essential tremor therapies. However, no application has been proposed for children despite their thinner skull being less of an acoustic barrier and the presence of a fontanelle on neonates, which could constitute a natural acoustic window for the transmission of ultrasound waves. As there is minimal literature data on the attenuation and speed-of-sound of the skull in neonatal patients, the aim of this study was to perform the acoustic characterization of a neonate skull.

\section{Methods}

A $0.2 \mathrm{~mm}$ needle acoustic hydrophone was placed in a tank of degassed water and aligned to the geometric focus of a clinical HIFU transducer (Philips Sonalleve). The signals of the 256 elements of the phased array transducer were acquired as a baseline measurement using this hydrophone. A degased cadaveric neonate skull was then placed inside the tank between the hydrophone and the transducer. Acquisitions were performed for different angular orientations of the skull according to the sagittal and coronal axes in the range of $\pm 15^{\circ}$. Insertion losses (IL) and time-of-flight (TOF) delays due to the skull and the fontanelle were deducted from these measurements performed at $1 \mathrm{MHz}$ and $1.2 \mathrm{MHz}$.

${ }^{1}$ Centre for Image Guided Innovation and Therapeutic Intervention, Toronto, Canada

Full list of author information is available at the end of the article

\section{Results and conclusions}

When the acoustic axis of the transducer was normal to the fontanelle, the average IL and TOF delay due to the fontanelle were respectively $0.9 \pm 0.8 \mathrm{~dB}$ and $-0.09 \pm$ $0.02 \mu \mathrm{s}$ at $1 \mathrm{MHz}$. At $1.2 \mathrm{MHz}$, the IL decreased at $0.5 \pm$ $0.5 \mathrm{~dB}$ and the TOF delay remained the same. Rotations of the skull around the coronal axis giving access to the parietal and frontal bones, their average IL were respectively $1.6 \pm 0.7 \mathrm{~dB}$ and $2.9 \pm 1.1 \mathrm{~dB}$ at $1 \mathrm{MHz}$ and $1.2 \pm 0.5 \mathrm{~dB}$ and $2.0 \pm 0.7 \mathrm{~dB}$ at 1.2 MHz. Rotations of the skull around the sagittal axis allowed the measurements of the properties of the bones on the left and the right sides of the skull. The average IL of the bones on the left side was $2.0 \pm$ $0.8 \mathrm{~dB}$ at $1 \mathrm{MHz}$ and $1.2 \mathrm{MHz}$. The average IL of the bones on the right side was $2.1 \pm 0.7 \mathrm{~dB}$ at $1 \mathrm{MHz}$ and at $1.7 \pm$ $0.4 \mathrm{~dB}$ at $1.2 \mathrm{MHz}$. The average TOF delay due to the skull bones was globally the same and was $-0.17 \pm 0.02 \mu \mathrm{s}$ at 1 $\mathrm{MHz}$ and $1.2 \mathrm{MHz}$. For the two studied frequencies, low $\mathrm{IL}$ and TOF delay values were obtained for the fontanelle and to a lesser extent for the skull bones. Slightly higher IL were obtained at $1 \mathrm{MHz}$ compared to $1.2 \mathrm{MHz}$. These results confirm that the fontanelle can act as an acoustic window for future TcMRgFUS applications. They also emphasise the potential of this technology for neurological disorder treatments on neonate patients.

Acknowledgements (Funding)

We acknowledge funding provided by the Brain Canada Multi-investigator Research Initiative, and the Focused Ultrasound Foundation. In-kind technical support provided by Philips Healthcare. 


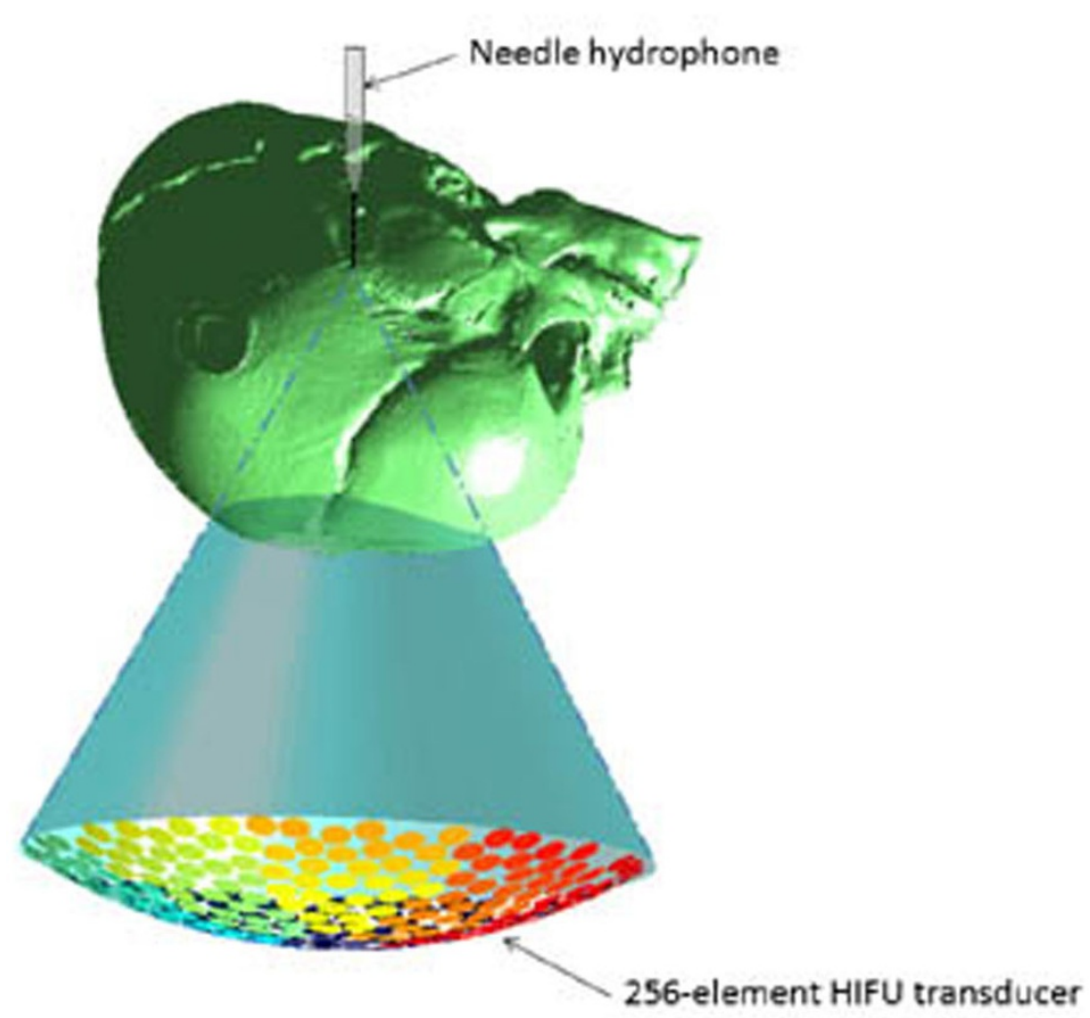

Figure 1 Computer rendering showing the skull and hydrophone positioning relative to the HIFU transducer beam

\section{Authors' details}

${ }^{1}$ Centre for Image Guided Innovation and Therapeutic Intervention, Toronto, Canada. ${ }^{2}$ Philips Healthcare Canada, Toronto, Canada. ${ }^{3}$ Thunder Bay Regional Research Institute, Thunder Bay, Canada.

Published: 30 June 2015

doi:10.1186/2050-5736-3-S1-P14

Cite this article as: Colas et al:: Acoustic characterization of a neonate skull using a clinical MR-guided high intensity focused ultrasound system for pediatric neurological disorder treatment planning. Journal of Therapeutic Ultrasound 2015 3(Suppl 1):P14.

\section{Submit your next manuscript to BioMed Central} and take full advantage of:

- Convenient online submission

- Thorough peer review

- No space constraints or color figure charges

- Immediate publication on acceptance

- Inclusion in PubMed, CAS, Scopus and Google Scholar

- Research which is freely available for redistribution

Submit your manuscript at www.biomedcentral.com/submit 